\title{
Google Earth Engine-Based Identification of Flood Extent and Flood- Affected Paddy Rice Fields Using Sentinel-2 MSI and Sentinel-1 SAR Data in Bihar State, India
}

\author{
Himanshu Kumar $^{1,4}$ (D) Sateesh Kumar Karwariya ${ }^{2,3} \cdot$ Rohan Kumar $^{4}$ \\ Received: 17 February 2021 / Accepted: 18 December 2021 / Published online: 19 January 2022 \\ (C) Indian Society of Remote Sensing 2022
}

\begin{abstract}
Flood is the major cause of fatalities associated with natural disasters in the world. In India especially in the state of Bihar, where about half of the area (North Bihar) gets flooded every year due to the overflow of major rivers during the rainy season. Which severely affects human lives, properties, agricultural production, farmers and their livelihood. Usually, the basins of the Kosi and Gandak rivers are known for their worst affects in Bihar. Synthetic aperture radar (SAR) is widely used for robust monitoring of flood events due to its ability to image the surface of the earth in all weather conditions. However, limited studies are available on flood patterns of Bihar and their impact on agriculture. Here, we investigated the flood extents and affected paddy rice fields for Bihar during the months of June-October (2020) using all accessible Sentinel-1 SAR and Sentinel-2 MSI images with additional supporting datasets available on the Google Earth Engine. The study showed that a large portion of Bihar $\left(7019 \mathrm{~km}^{2}\right)$ was submerged during monsoon season. The floodwater remains in the agricultural fields for 50 to 65 days causing severe damage to the Kharif crops, mainly rice. The extreme effect of flood was seen in agricultural lands (11.23\% of the total area) and populations (15.56\% of the total population) in Bihar. Satellite-based identification of flood progression and affected rice fields can be helpful for decision-makers at the time of disaster to prioritize relief and rescue operations.
\end{abstract}

Keywords Flood · Google Earth Engine $\cdot$ Paddy field $\cdot$ Rice $\cdot$ Sentinel-1 SAR $\cdot$ Sentinel-2 MSI

Himanshu Kumar

himanshukumar.gis@gmail.com

Sateesh Kumar Karwariya

sateesh.karwariya@gmail.com

Rohan Kumar

rohan.25322@lpu.co.in

1 ICAR-National Dairy Research Institute, Karnal, HR 132001, India

2 Commissionerate of Rural Development, Government of Gujarat, Gandhinagar, India

3 Present Address: SAC-Indian Space Research Organization, Ahmedabad, India

4 Lovely Professional University, Phagwara, India

\section{Introduction}

In the Indian subcontinent, flooding is a widespread, natural disaster and recurring event. The geographical and riverine structures increase the risk of flooding and make the country prone to flooding. Rapid unplanned urbanization, climate change, change in land use/land cover (LULC), irregular rainfall are the main cause of recurring floods that affects millions of people's lives, infrastructures, economics and local ecosystems. Even during the Covid-19 epidemic, people are forced to migrate from the state of Bihar due to floods for employment to meet their basic needs.

In Bihar, nearly $76 \%$ population are dependent on agriculture which is severely affected by concurrent floods (Anonymous, 2020a, b, c). There is a lack of an effective flood monitoring and early warning system due to poor availability of resources in developing countries like India (Wu et al., 2012). Flood intensity has been increasing 
from the last three decades (Freer et al., 2013), therefore the role of remote sensing is crucial for flood mapping, monitoring and model development to monitor the impact of flood.

Over the years, remote sensing satellite data is capable of monitoring flood extent, intensity, progression and deterioration on a real-time basis. For flood-related mapping synthetic aperture radar (SAR) data having upper edge than multispectral optical data, because of its allweather and day-night sensing capability. In the year 2014-2016, Sentinel-1A/B satellites were launched by European space agency (ESA) (Torres et al., 2012). It is first-ever global SAR mission, whose datasets are open access for the global public and researchers. It has $10 \mathrm{~m}$ spatial and six days temporal resolution, which helps for rapid flood mapping within the short time frame. Remotely sensed Earth Observation (EO) data and products were used for monitoring flooded regions which are gradually used in the operational purpose for disaster management (Schumann et al., 2018; Voigt et al., 2016). Due to spatial and temporal characteristics of remote sensing data, it can be used to acquire the essential information from geomorphological features of rivers. This information can be beneficial for mitigation measures in the time of disaster. For different analysis, multiple sources of satellite data are freely available. However, due to resource unavailability, the downloading, storing and processing of satellite data is a big task for users.

Hence to overcome these problems, Google launched the most advanced cloud-based geospatial processing platform "Google Earth Engine (GEE)". It enables to access high-performance computational resources to process satellite data without the requirement of local storage, in addition to allowing up to date remote sensing databases for scientific and academic purposes (Gorelick et al., 2017; Schumann et al., 2018). It enables to share the developed codes of different analysis to multiple users and researchers. The Google Earth Engine (GEE), introduced by Google, Inc., as a new computing platform for large-scale data processing such as the time series data analysis of Landsat archive (Gorelick et al., 2017). GEE platform hosted a complete, up-to-date and ready SAR data archive of Sentinel-1A/B Ground Range Detected (GRD) data.

In our study, we used Sentinel-1A/B SAR and Sentinel2A/B MSI datasets. Sentinel-2A/B MSI was used for LULC mapping and Sentinel-1A/B for flood and floodaffected paddy rice mapping and monitoring. The capability of SAR sensors to identify flood progression and flood-affected paddy fields depends on various scattering mechanisms. For the identification of inundated pixels, several SAR-based flood identification techniques used scattering mechanism by applying backscatter thresholds to

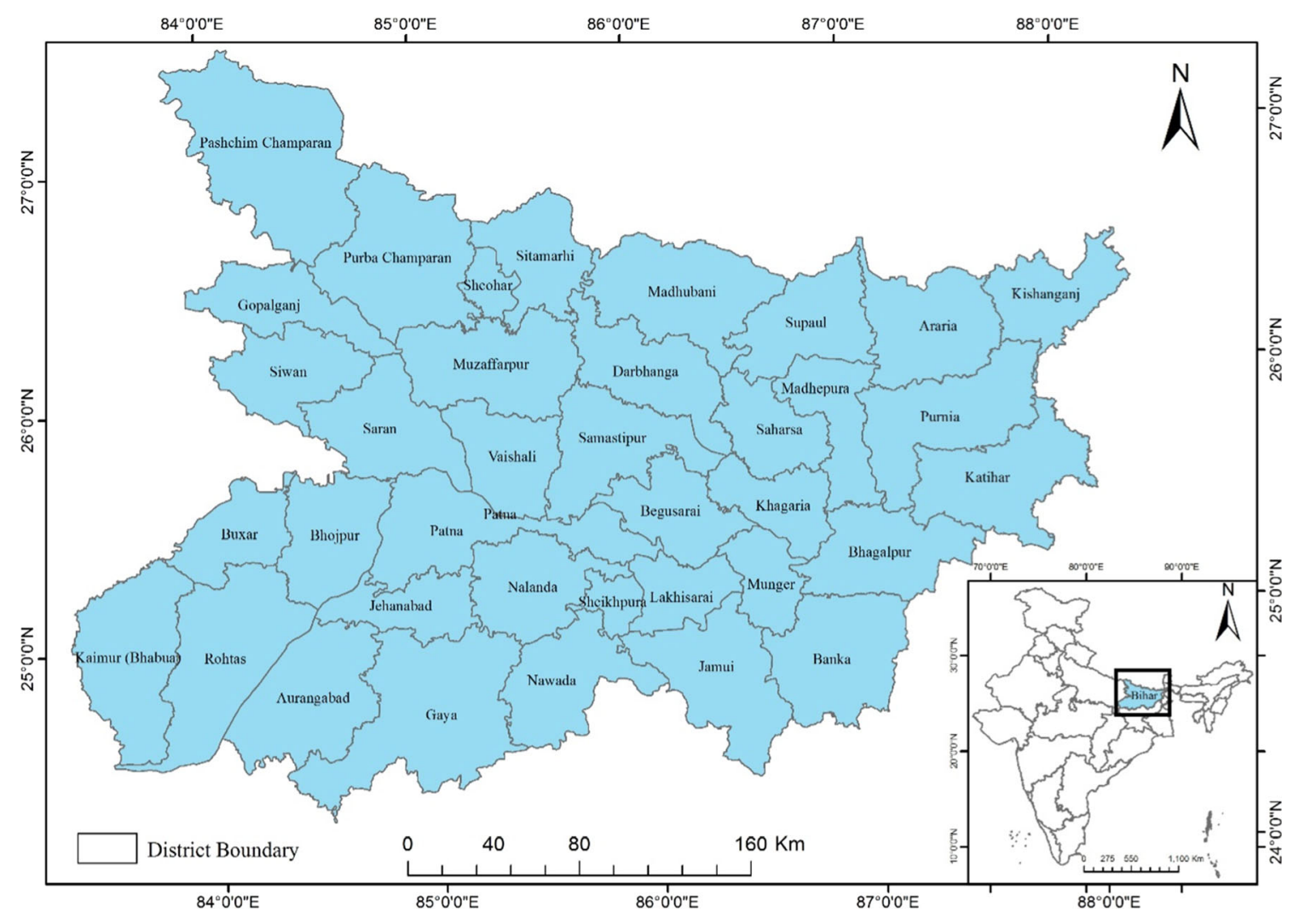

Fig. 1 Location map of study area 
satellite imagery (Chini et al., 2017). Typically, the change detection method is used to identify flooded pixels using SAR data.

Similarly, various techniques and indices are available to extract water bodies using optical and SAR satellite imageries (Alejandro Tobón-Marín \& Julio Cañón Barriga, 2020). The Normalized Difference Water Index (NDWI) (McFeeters, 1996), Modified Normalized Difference Water Index (MNDWI) (Xu 2006), and recently developed, the Automated Water Extraction Index (AWEI) (Feyisa et al., 2014) are the most popular indices method for extracting water bodies.

Over the years several studies have been conducted using optical and SAR satellite datasets to investigate recurring flood events in Bihar to minimize its impact (Sinha et al., 2008 and Martinis et al., 2013).

The objective of this study is to explore GEE to rapidly demarcate the flooded area during the 2020 flood event and to develop an algorithm for tracking flood movement of Bihar. Satellite Imageries during March 2020 is used for pre-flooding and from June to October 2020 for flood. Then, subtracted flooded layer from pre-flood layer in GEE platform.

\section{Materials and Methods}

\section{Study Area}

In India, Bihar is one of the most flood-prone state. It covers a landmass of approximately 94,163 sq. $\mathrm{km}$ and extends between $24^{\circ} 20^{\prime} 10^{\prime \prime}$ to $27^{\circ} 31^{\prime} 15^{\prime \prime} \mathrm{N}$ latitude and $83^{\circ} 19^{\prime} 50^{\prime \prime}$ to $88^{\circ} 17^{\prime} 40^{\prime \prime} \mathrm{E}$ longitude (Fig. 1). The total population of Bihar is about 10,38,04,637 with a density of $1,102 / \mathrm{km}^{2}$ (Census of India, 2011). The state has an average annual rainfall of $1205 \mathrm{~mm}$ with average 52.5 rainy days and has sandy loam, loam, clay and clay loam soils (DAC\&FW, GoI, 2020). The summers are generally quite hot and winters are fairly cool (DAC\&FW, GoI, 2020). The study area comprises 21 districts of Bihar.
Kosi, Gandak, Burhi Gandak, Bagmati and Mahananda river are the main cause of flood in Bihar. North Bihar gets flooded every year due to heavy rainfall in the basin of these rivers. The Kosi river is called "Sorrow of Bihar" due to recurring floods and frequent changes in their course. The major crops grown in the state are rice, wheat and maize. Paddy is the main crop of rainy season and is cultivated in almost all the districts of Bihar, which is usually destroyed due to severe floods (Anonymous, 2020a, b, c).

\section{Data Used (Table 1)}

\section{Sentinel-1 SAR Data and Processing}

In this study, freely available Sentinel-1A/B SAR C-band $(5.4 \mathrm{GHz})$ data provided by the European Space Agency (ESA) (SciHub; https://scihub.copernicus.eu) was used. The Sentinel-1 data has a repeativity frequency of 12 days with one satellite and 06 days with two satellites. It is available in four modes, which is Stripmap (SM), Interferometric Wide swath (IW), Extra-Wide swath (EW) and Wave (WV) while more descriptions are available in (Torres et al., 2012).

The IW mode has been used in our study which is the main acquisition mode for the land surface that meets contemporary service requirements with long-term archives (Torres et al., 2012). Its conflict-free modes with $\mathrm{VV}+\mathrm{VH}$ (vertical transmit, vertical receive (VV) and vertical transmit, horizontal receive $(\mathrm{VH})$ polarisation.

The Sentinel-1 dataset is hosted on the GEE platform and the available tool of SNAP software package was used for pre-processing. GEE platform has been used to perform all the tasks required for SAR satellite data processing. GEE platform was also used to execute orbit correction, Noise removal, radiometric calibration, terrain corrections using SRTM data and converted backscatter intensity to decibels $(\mathrm{dB})$ according to

$\sigma^{\circ}=10 * \log _{10} \sigma^{\circ}$

Table 1 Datasets used in study

\begin{tabular}{|c|c|c|c|c|c|}
\hline Datasets & Period & Resolution & Provided by & Purpose & $\begin{array}{l}\text { GEE assess } \\
\text { Address }\end{array}$ \\
\hline $\begin{array}{l}\text { Sentinel-1 (SAR) satellite } \\
\text { data }\end{array}$ & $\begin{array}{l}\text { June-October } \\
\quad(2020)\end{array}$ & $10 \mathrm{~m}$ & $\begin{array}{l}\text { European Space } \\
\text { Agency (ESA) }\end{array}$ & $\begin{array}{l}\text { To extract flood extent and flood } \\
\text { affected paddy rice field }\end{array}$ & $\begin{array}{l}\text { COPERNICUS/ } \\
\text { S1_GRD }\end{array}$ \\
\hline $\begin{array}{l}\text { Sentinel-2 (MSI) satellite } \\
\text { data }\end{array}$ & March (2020) & $10 \mathrm{~m}$ & $\begin{array}{l}\text { European Space } \\
\text { Agency (ESA) }\end{array}$ & LULC Map & $\begin{array}{l}\text { COPERNICUS/ } \\
\text { S2 }\end{array}$ \\
\hline $\begin{array}{l}\text { Shuttle Radar Topography } \\
\text { Mission (SRTM) }\end{array}$ & 2000 & $30 \mathrm{~m}$ & NGA and NASA & Terrain correction & $\begin{array}{l}\text { USGS/ } \\
\text { SRTMGL1_003 }\end{array}$ \\
\hline
\end{tabular}




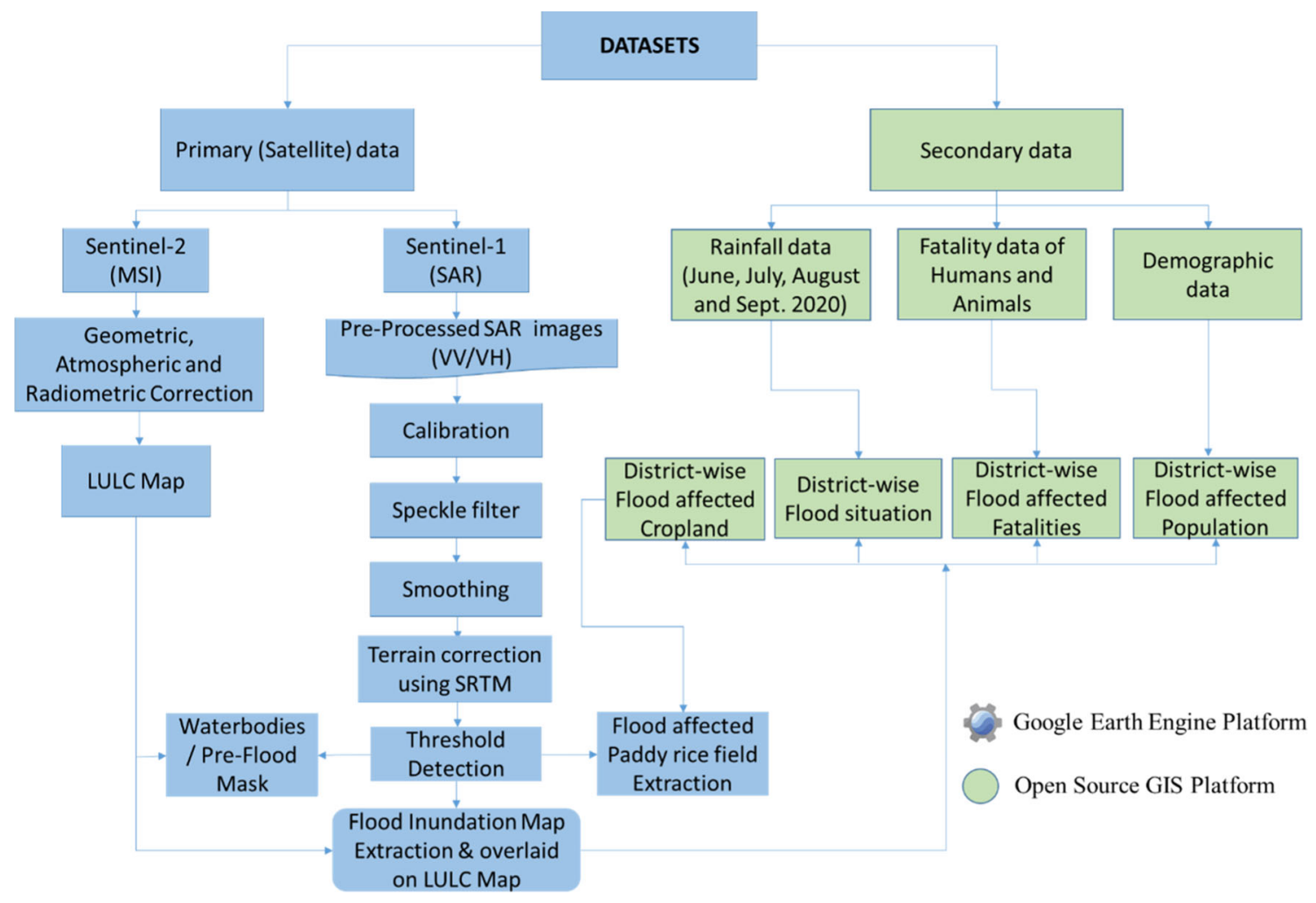

Fig. 2 Methodology of study

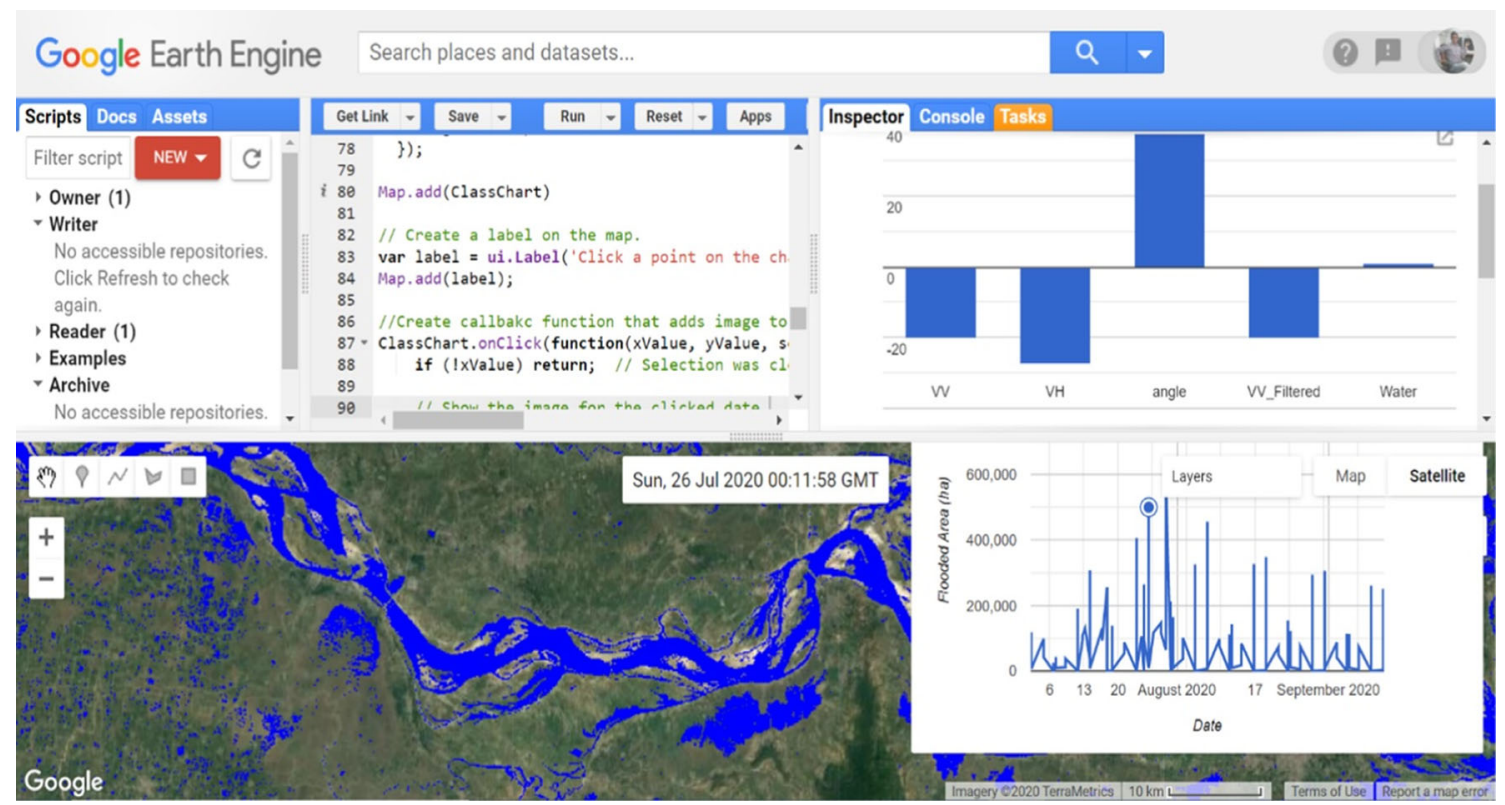

Fig. 3 Google Earth Engine Interface

We used all the available Sentinel-1 SAR imageries for flood mapping, monitoring and flood-affected paddy rice fields, pre-flood period (March 20 to May 20, 2020) and the peak flood period (July 01 to October 16, 2020).

\section{Sentinel-2 MSI}

Publicly available, ESA's Sentinel-2A/B MSI satellite data are capable of monitoring land surface conditions. Its 
Fig. 4 Inundated area and Rainfall
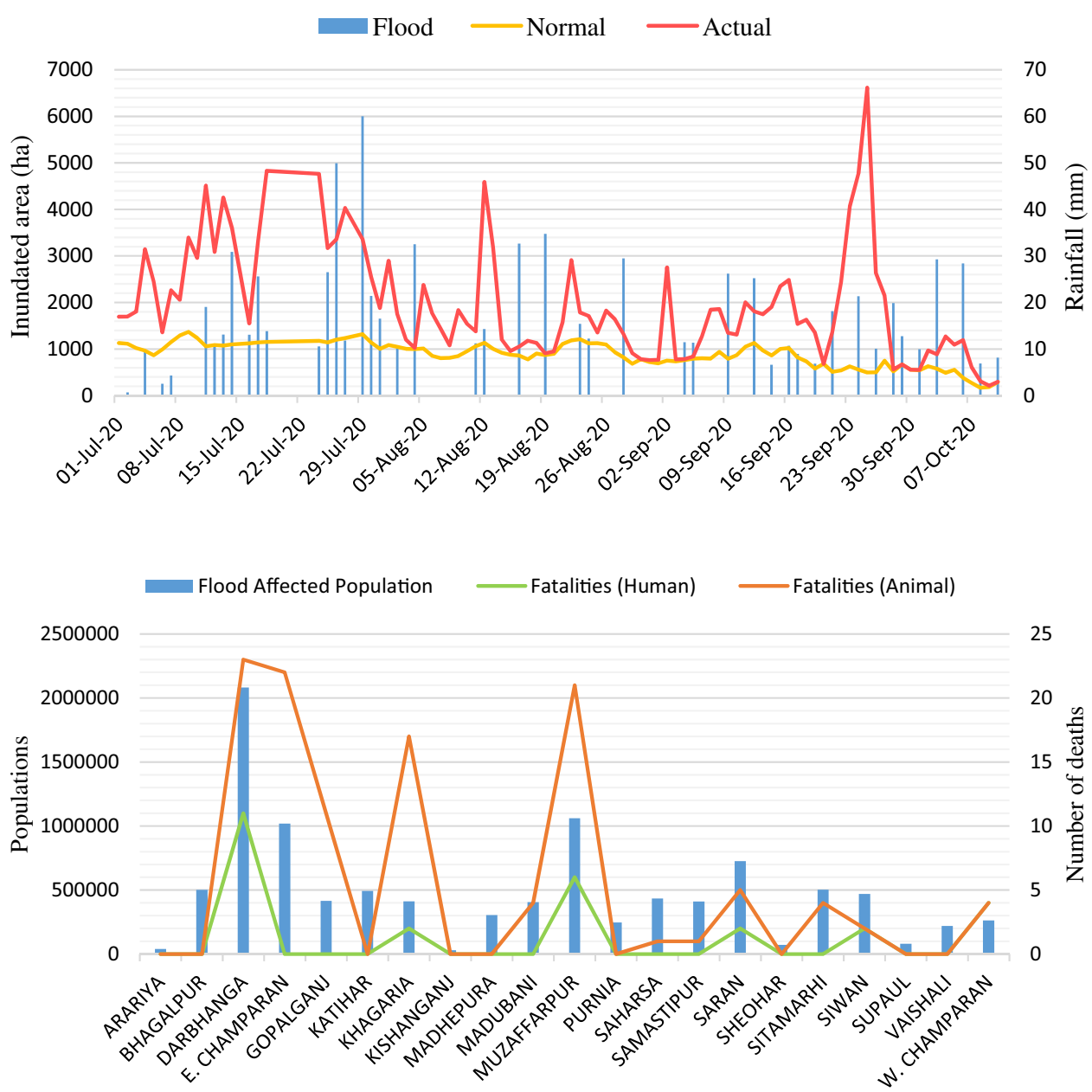

Fig. 5 Affected Populations and fatalities revisit time is 10 days with one satellite and 5 days with two satellites. Its spatial resolution is $10 \mathrm{~m}$ (bands: 2, 3, 4 and 8), $20 \mathrm{~m}$ (bands: 5, 6, 7, 8a 11 and 12) and $60 \mathrm{~m}$ (bands: 1, 9 and 10). In this study, we used band 2, 3, 4 and 8 of Sentinel-2A/B MSI satellite data for LU/LC mapping. We selected images of March 2020 for the least cloud cover $(<10 \%$ cloud cover $)$ using "CLOUDY_PIXEL_PERCENTAGE" tool of GEE. Further, the QA band of Sentinel-2 was used to remove clouds cover (Singha et al., 2020).

Finally, all the available images were used for LU/LC mapping of Bihar during 2020. Sentinel-2 MSI based Land Use/Land Cover used to assume the impact of flood inundation on LU/LC especially on cropland and paddy rice fields.

\section{Other Datasets}

We have also used IMD (IMD, 2020)/India-WRIS (2020) data for rainfall observations, Population data from Census of India (Census of India, 2011), Global Human Settlement Layer (GHSL) by European Commission (JRC, 2015) and
Fatalities data from State Disaster Management Department, Bihar (Anonymous, 2020b).

\section{Methodology}

Here, we used Sentinel-1 SAR data to identify the flood extent and flood-affected rice fields. LU/LC map has been generated using Sentinel-2A/B MSI data to extract floodaffected cropland, pre-flood waterbodies and other classes. We used thresholding method to extract inundated pixels. The intensity within the threshold range was classified as flood, while the pixels with intensity above the threshold were classified as non-flooding. Then, the obtained flood extent has been subtracted by the pre-flood layer of water bodies which is derived from the LU/LC layer for the elimination of water bodies. A flowchart of the methodology is shown in Fig. 2.

The entire analysis has been performed in the GEE cloud platform using SNAP Software package. After preprocessing, a web-based IDE code has been developed by JavaScript code (https://code.earthengine.google.com/ ?scriptPath=users $\% 2$ Fhimpria\%2FFlood_only\%3AFlood_ 


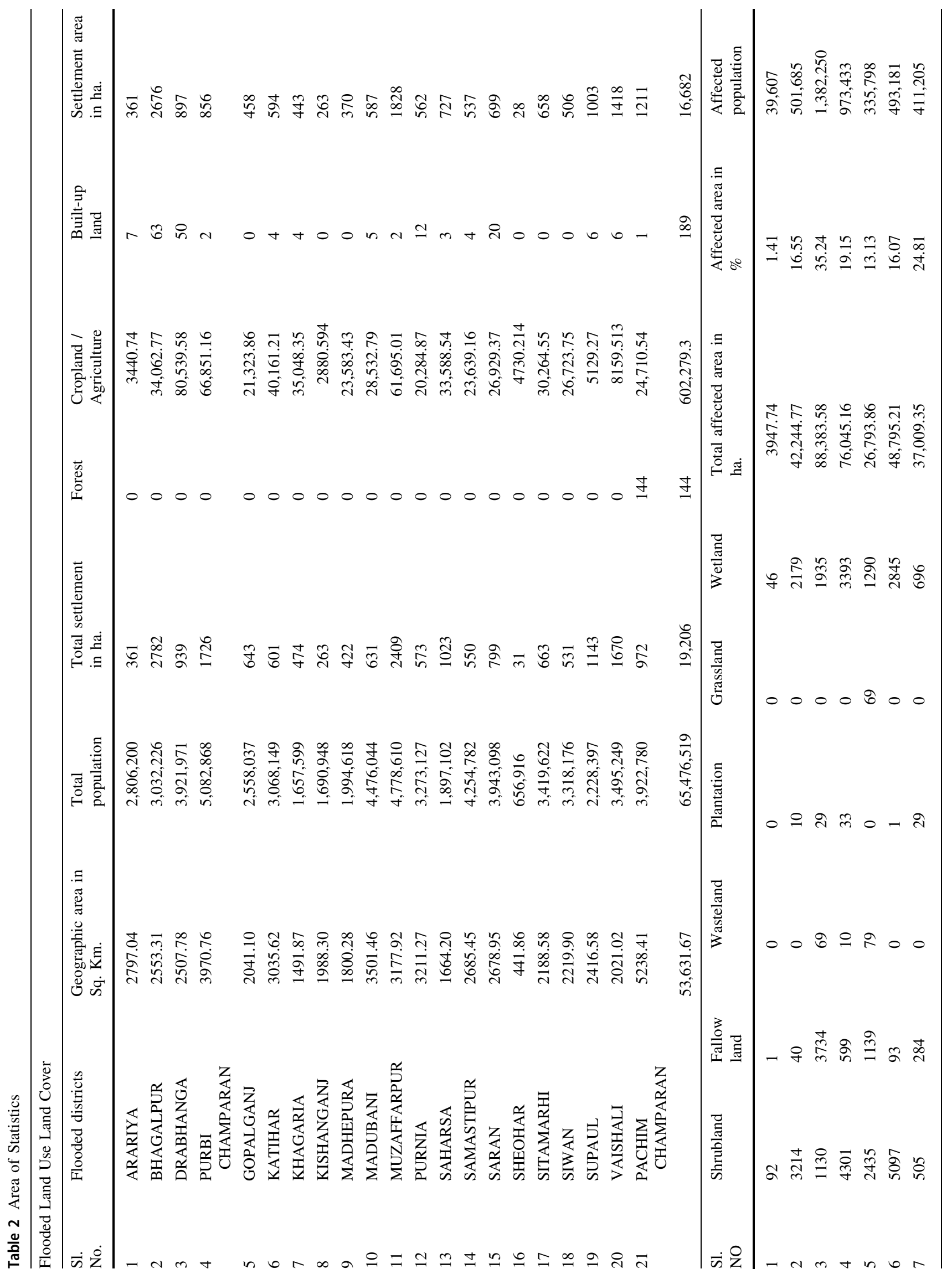






20_10_19_share) to estimate flooded areas and flood-affected paddy fields (Fig. 3.).

The key benefit of GEE is that space and time needed for data acquisition, analysis and processing can be significantly reduced (Dineshkumar et al., 2019). This advantage of the GEE cloud platform makes it appropriate for mapping and monitoring flood events and flood-affected rice fields. Finally, the inundation layer obtained is further refined using open source GIS tools.

\section{Results and Discussion}

The present analysis of recent floods in Bihar during July to October 2020 was carried out using Sentinel-1 SAR, Sentinel-2 MSI data, rainfall observations from IMD data (IMD, 2020)/India-WRIS (2020), Population data from Census of India (Census of India, 2011), Global Human Settlement Layer (GHSL) by European Commission (JRC, 2015) and Fatalities data from State Disaster Management Department, Bihar (Anonymous, 2020b).

Bihar witnessed heavy and incessant rains during June to September 2020, causing severe flooding problems and loss of life and property in many parts of the state. Data from IMD/India-WRIS show heavy rainfall in river basins of Bihar during June to September 2020 especially over Kosi, Gandak and Ganga basins (Fig. 4.). Particularly, we found that about two weeks in July 2020 and one week in September 2020, which creates flood-like situations in the downstream regions of North Bihar.

About 21 districts of Bihar in the lower basin of Gandak, Ganga, Bagmati-Adhwara, Kamla-Balan, Kosi and Mahananda basin were on high alert due to rising water level above the danger mark (CWC, 2020). Satellite-based analysis of flood inundation will support in identification of worst affected districts in terms of submerged area, infrastructure and Flood-affected paddy rice field submerged due to the recent flooding event of 2020.

In Bihar, around 101,91,267 people in 21 districts have been affected by the flood situation so far 27 people and 88 animals have lost their lives due to floods (SDMD, Bihar, 2020; FMIS, Bihar, 2020). Darbhanga reported the highest number of flood-related human deaths (11), followed by Muzaffarpur (6), West Champaran (4) and two each in Saran and Siwan, according to the State Disaster Management Authority, Bihar. The highest animal casualties (22) were registered in Darbhanga district, followed by fifteen each in Khagria and Muzaffarpur, twelve in West Champaran and eleven in Gopalganj as per the State Disaster Management Authority, Bihar (Fig. 5.).

As per previous CWC gauge data records from 2000 onwards, Bihar used to witness severe flooding events during August and September and by the end of September 

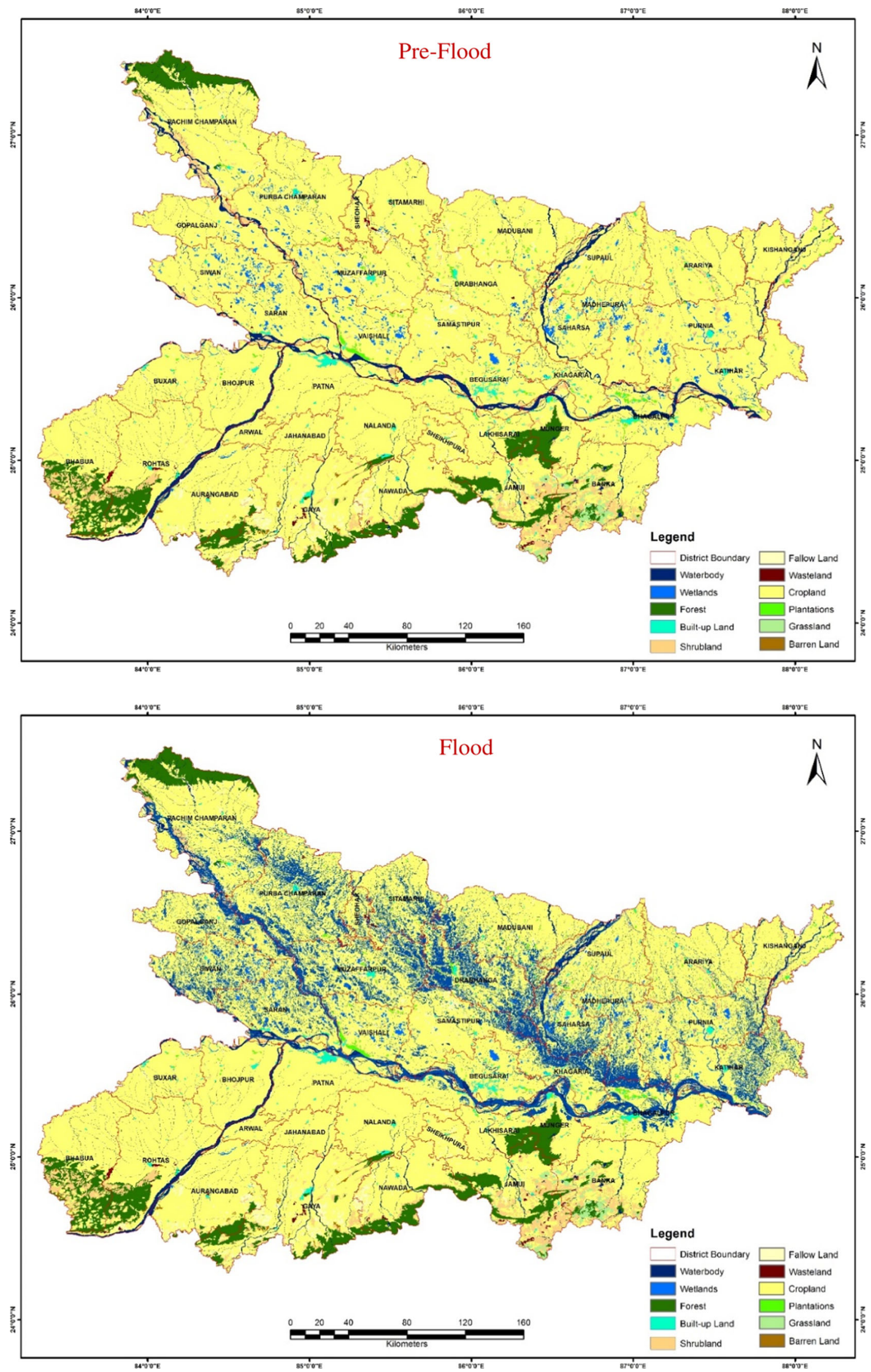

Fig. 6 Landuse/Landcover map showing the effect of Flood 
Fig. 7 District wise flood statistics

Fig. 8 Paddy rice field destroyed by flood

Fig. 9 Backscatter response of different polarization
- Total Flooded Area
Total Flooded Cropland
- Total Flood-affected Paddy Rice Field
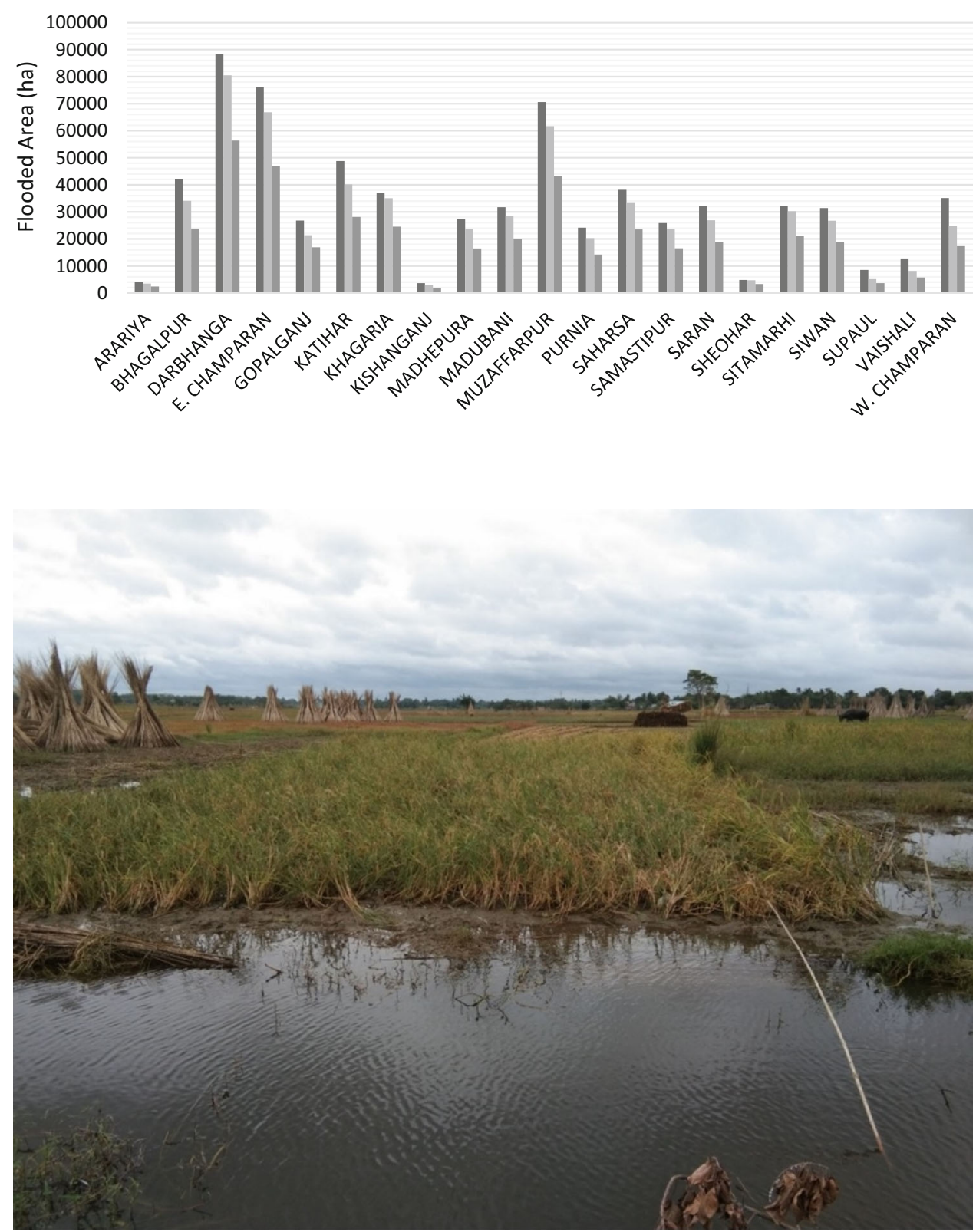

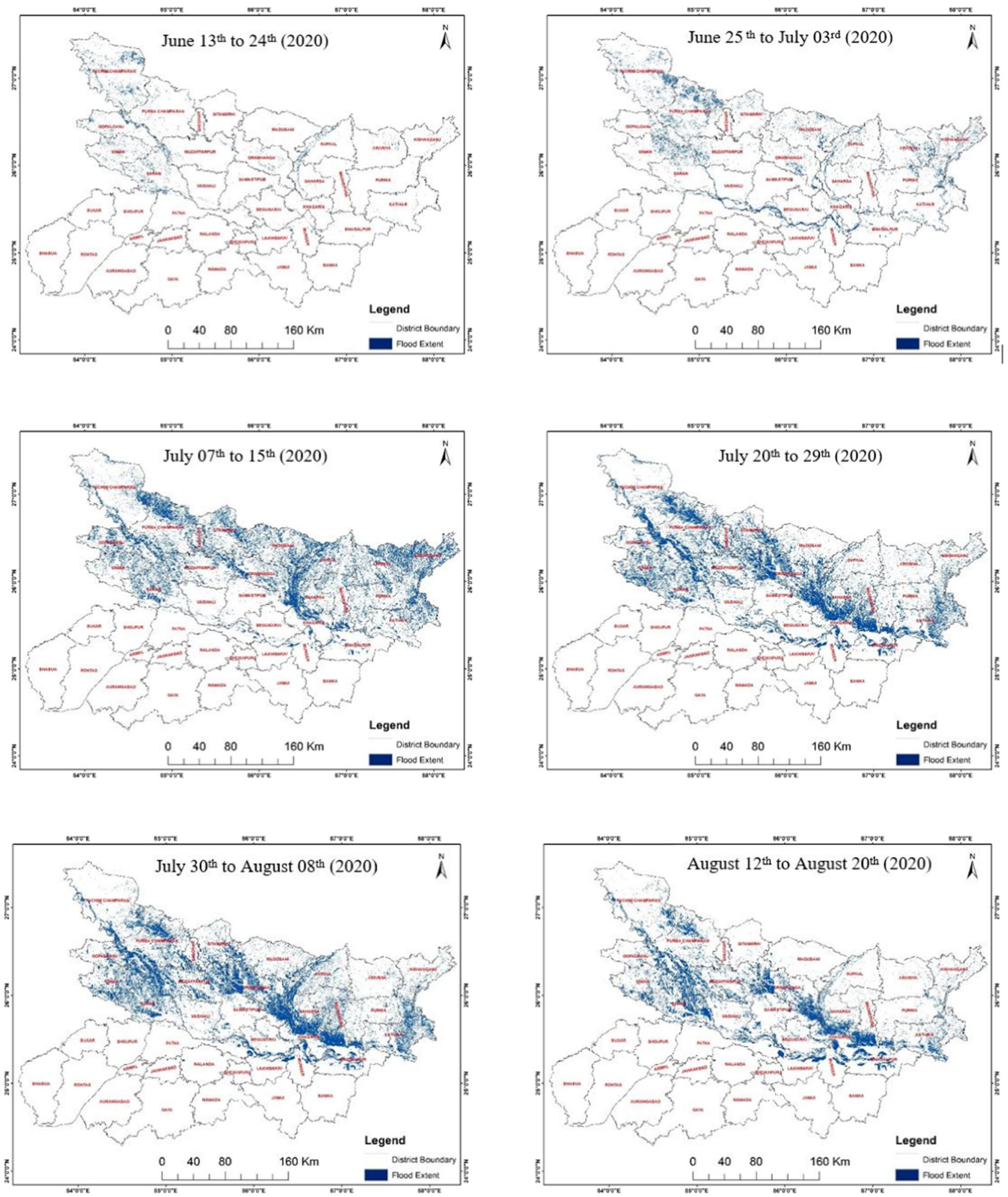

Fig. 10 Flood progression during July to September 2020 

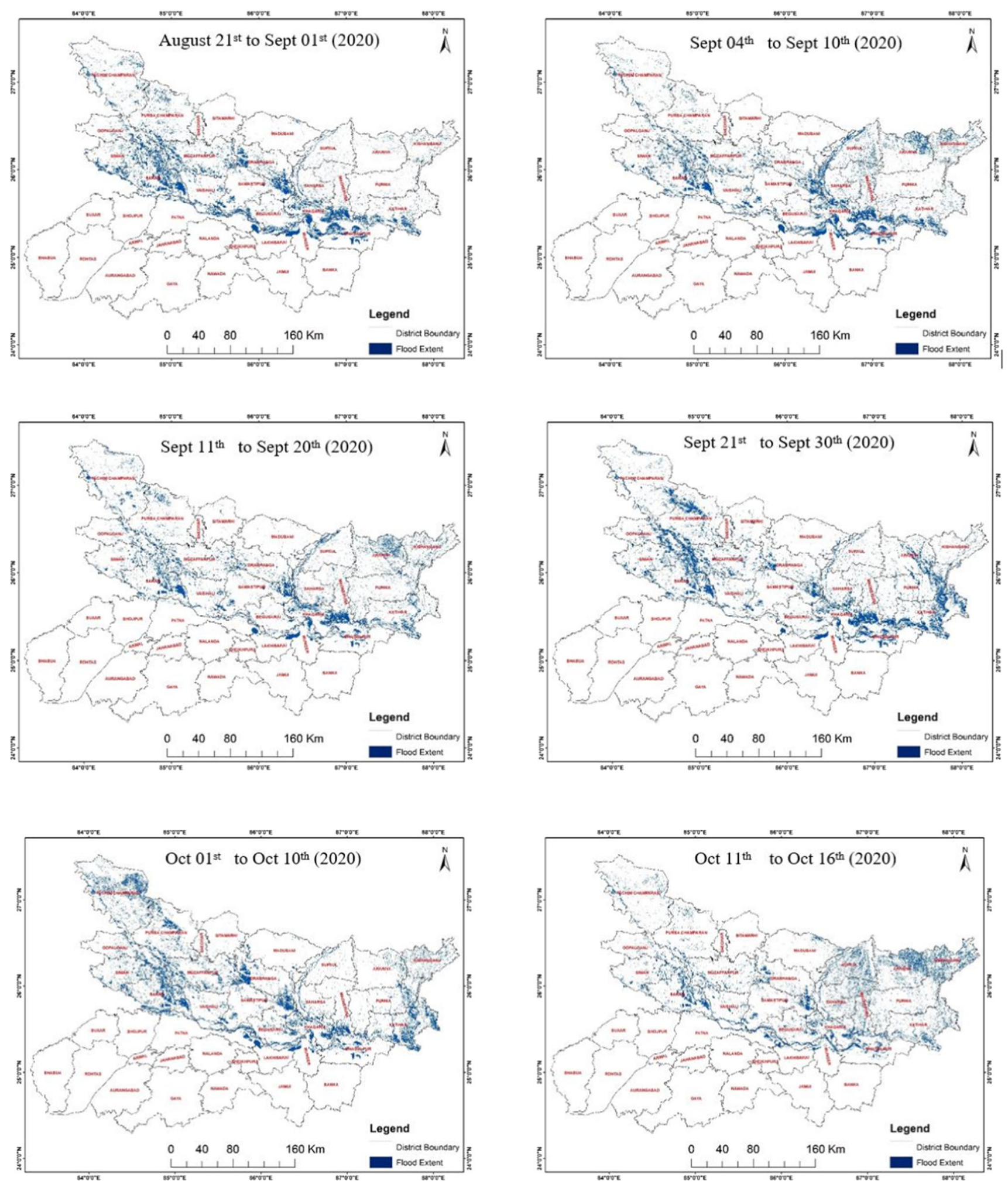

Fig. 10 continued 
Table 3 Accuracy assessment

\begin{tabular}{lllllll}
\hline Class & Rice & None rice & Waterbodies & Total & Users accuracy $(\%)$ & Producers accuracy (\%) \\
\hline Rice & 301 & 10 & 5 & 316 & 95.25 & 94.36 \\
None Rice & 16 & 195 & 3 & 214 & 91.12 & 93.75 \\
Waterbodies & 2 & 3 & 95 & 100 & 95.00 & 92.23 \\
Total & 319 & 208 & 103 & 630 & & \\
\hline
\end{tabular}

Overall Classification Accuracy $=93.81 \%$ and Kappa Coefficient $=0.70$

and early October flooding events declined (CWC, 2020; NIDM, Bihar Flood Report -2007, India-WRIS, 2020 and IMD, 2020). However, the present flooding event in July to October shows the long duration and shift in the flooding pattern.

This study has been performed with an objective to assess the cumulative flood inundation extent, flood effect on LULC (Especially on Paddy rice field) by recent floods (July to October 2020) in Bihar (Table 2).

The analysis shows that about 7,01,942 hectares area of the state was under submergence during July 22 to October 09, 2020. About twenty-one districts were observed to be impacted by flooding. In terms of area under submergence three districts had more than 70,000 ha area submerged, two districts between 40,000 and 50,000 ha, seven districts between 30,000 and 40,000 ha, four districts between 20,000-30,000 ha and five districts less than 13,000 ha (Figs. 6 and 7.).

Darbhanga, West Champaran and Muzaffarpur district were the worst affected districts having 88,383, 76,045 and 70,620 ha, respectively, under submergence. Out of the total inundated land about 6.02 Lakh cropland/agricultural land was submerged (Figs. 6 and 7.).

Districts like Darbhanga, East Champaran, Muzaffarpur, Gopalganj, Katihar, Saharsa, Khagaria, Sheohar, West Champaran, Saran and Siwan were observed to be inundated for about 55-65 days. So, Paddy rice fields have been totally destroyed (Fig. 8). Agriculture is a primary source of income in Bihar. About $76 \%$ population is engaged in agricultural works. As Bihar is facing flood disasters every year (NIDM, Bihar Flood Report -2007). Therefore, it is also a major reason for migration from Bihar to other states of India for employment.

\section{Sentinel-1 SAR Data-Based Flood Progression Assessment in North Bihar}

Flood progression in North Bihar based on Sentinel-1 SAR data from June to October 2020 were shown in Fig. 10. We used $\mathrm{VH}$ and $\mathrm{VV}$ polarization for flood delineation. Backscatter response of $\mathrm{VV}$ ranges between -8 and $16 \mathrm{~dB}$ whereas $\mathrm{HV}$ ranges between -16 and $-23 \mathrm{~dB}$ (Fig. 9).
Severe rainfall was started from June to till September and developed flood-like conditions for North Bihar. The extent of the flood shows the effects of rain-induced flooding in Fig. 10. Major areas were submerged from July 07 to 29, 2020. And again some parts of North Bihar were inundated during September 21 to 30 due to heavy rain in the river basin of North Bihar (Fig. 10).

\section{Accuracy Assessment}

The accuracy assessment was done on the classified image of North Bihar. The confusion matrix generated from classified image of North Bihar is represented in Table 3, the producer's accuracy (varying from 92.23 to $94.36 \%$, respectively), user's accuracy (varying from 91.12 to $95 \%$, respectively) and overall classification accuracy $(93.81 \%)$ with 0.70 Kappa Statistics. The accuracy was influenced by the neighbouring class which has the similar spectral profile.

\section{Conclusion}

In this paper, we have developed a web-based JavaScript code, which is able to process huge datasets hosted on GEE platform within a minutes for robust flood mapping, monitoring and estimation of flood-affected rice fields using SAR imagery at large-scale with all-weather capability. Here, we observed the concurrent floods (JulyOctober 2020) in Bihar, about 13.09\% (7019 $\left.\mathrm{km}^{2}\right)$ area are flooded and affected massive population $(10,19,1,267$ persons) with worst in Darbhanga $(53.08 \%)$, followed by Muzaffarpur (22.22\%) and East Champaran (20.06\%) of the total population. We also studied flood-affected paddy fields and found that the severely flood-affected paddy fields are about $70.33 \%(423,595.48$ ha) of the total crop. The accuracy assessment has been also performed for validation purpose and overall classification accuracy is $93.81 \%$ with 0.70 kappa statistics. The generated flood maps, estimated flood-affected rice fields and its area of statistics will be useful for policy-makers and preventive measures for disaster management. 
Acknowledgements The authors would like to thank European Space Agency (ESA) for providing the SAR data in Google Earth Engine for hassle-free cloud data processing with the API code.

Funding Research work is not funded by any organization.

Availability of Data and Material Data can be made available through user request.

Code Availability GEE Code can be made available through user request.

\section{Declarations}

Conflict of interest Authors declare no financial and competing interests.

\section{References}

Anonymous (2020a). Retrieved from http://drdpat.bih.nic.in/PATable-04-Bihar.htm, 2020.

Anonymous (2020b). State Disaster Management Department, Bihar. Retrieved from http://disastermgmt.bih.nic.in/cumulative\% 20flood\%20report\%202020/cum05092020.pdf

Anonymous (2020c). Retrieved from https://farmech.dac.gov.in/Farm erGuide/BI/index1.html, 2020.

Census of India (2011). (https://censusindia.gov.in/2011-prov-results/ data_files/bihar/Provisional\%20Population\%20Totals\%202011Bihar.pdf).

Central Water Commission (2020). Daily Flood Situation Report cum Advisories, Government of India, New Delhi. Retrieved from http://cwc.gov.in/fmo/dfsra, 2020.

Chini, M., Hostache, R., Giustarini, L., \& Matgen, P. (2017). A hierarchical split-based approach for parametric thresholding of SAR images: Flood inundation as a test case. IEEE Transactions on Geoscience and Remote Sensing, 55(12), 6975-6988. https:// doi.org/10.1109/TGRS.2017.2737664

Department of Agriculture, Cooperation \& Farmers Welfare (DAC\&FW) (https://farmech.dac.gov.in/FarmerGuide/BI/1.htm) (2020).

Dineshkumar, C., Satish Kumar, J., \& Nitheshnirmal, S. (2019). Rice Monitoring Using Sentinel-1 Data in the Google Earth Engine Platform. Multidisciplinary Digital Publishing Institute Proceedings. https://doi.org/10.3390/IECG2019-06206

European Commission, Joint Research Centre (JRC); Columbi Global Human Settlement Layer (GHSL)a University, Center for International Earth Science Information Network - CIESIN (2015): GHS population grid, derived from GPW4, multitemporal (1975, 1990, 2000, 2015). European Commission, Joint Research Centre (JRC) PID: http://data.europa.eu/89h/jrc-ghslghs_pop_gpw4_globe_r2015a

Feyisa, G. L., Meilby, H., Fensholt, R., \& Proud, S. R. (2014). Automated Water Extraction Index: A new technique for surface water mapping using Landsat imagery. Remote Sensing of Environment, 140, 23-35. https://doi.org/10.1016/j.rse.2013.08. 029

Flood Management Information System (2020). Bihar

Freer, J., Beven, K., Neal, J., Schumann, G., Hall, J., \& Bates, P. (2013). Flood risk and uncertainty. In J. Rougier, S. Sparks, \& L. Hill (Eds.), Risk and Uncertainty Assessment for Natural
Hazards (pp. 190-233). Cambridge University Press. https:// doi.org/10.1017/CBO9781139047562.008

Gorelick, N., Hancher, M., Dixon, M., Ilyushchenko, S., Thau, D., \& Moore, R. (2017). Google Earth Engine: Planetary-scale geospatial analysis for everyone. Remote Sensing of Environment, 202, 18-27. https://doi.org/10.1016/j.rse.2017.06.031

Indian Metrological Department (IMD) report and advisory, Bihar (2020)

India-WRIS. Retrieved from (https://indiawris.gov.in/wris/\#/rainfall), 2020.

Martinis, S., Twele, A., Strobl, C., Kersten, J., \& Stein, E. (2013). A multi-scale flood monitoring system based on fully automatic MODIS and TerraSAR-X processing chains. Remote Sensing, 5(11), 5598-5619. https://doi.org/10.3390/rs5115598

McFeeters, S. K. (1996). The use of the Normalized Difference Water Index (NDWI) in the delineation of open water features. International Journal of Remote Sensing, 17(7), 1425-1432. https://doi.org/10.1080/01431169608948714

National Institute of Disaster Management (NIDM), Bihar Flood Report -2007

Schumann, G. J., Brakenridge, G. R., Kettner, A. J., Kashif, R., \& Niebuhr, E. (2018). Assisting flood disaster response with earth observation data and products: A critical assessment. Remote Sensing, 10(8), 1230. https://doi.org/10.3390/rs10081230

SciHub; https://scihub.copernicus.eu

Singha, M., Dong, J., Sarmah, S., You, N., Zhou, Y., Zhang, G., Doughty, R., \& Xiao, X. (2020). Identifying floods and floodaffected paddy rice fields in Bangladesh based on Sentinel-1 imagery and Google Earth Engine. ISPRS Journal of Photogrammetry and Remote Sensing, 166, 278-293. https://doi.org/ 10.1016/j.isprsjprs.2020.06.011

Sinha, R., Bapalu, G. V., Singh, L. K., \& Rath, B. (2008). Flood risk analysis in the Kosi river basin, north Bihar using multiparametric approach of Analytical Hierarchy Process (AHP). $J$. Indian Soc. Remote Sens., 36, 335-349. https://doi.org/10.1007/ s12524-008-0034-y

Tobón-Marín, A., \& Cañón Barriga, J. (2020). Analysis of changes in rivers planforms using google earth engine. International Journal of Remote Sensing, 41(22), 8654-8681. https://doi.org/ 10.1080/01431161.2020.1792575

Torres, R., Snoeij, P., Geudtner, D., Bibby, D., Davidson, M., Attema, E., Potin, P., \& Traver, I. N. (2012). GMES Sentinel-1 mission. Remote Sensing of Environment, 120, 9-24. https://doi.org/10. 1016/j.rse.2011.05.028

Voigt, S., Giulio-Tonolo, F., Lyons, J., Kučera, J., Jones, B., Schneiderhan, T., Platzeck, G., Kaku, K., Hazarika, M.K., Czaran, L., Li, S., Pedersen, W., James, G.K., Proy, C., Muthike, D.M., Bequignon, J., Guha-Sapir, D. (2016). Global trends in satellite-based emergency mapping Science. https://doi.org/10. 1126/science.aad8728

Wu, H., Adler, R. F., Hong, Y., Tian, Y., \& Policelli, F. (2012). Evaluation of global flood detection using satellite-based rainfall and a hydrologic model. Journal of Hydrometeorology, 13, 1268-1284. https://doi.org/10.1175/JHM-D-11-087.1

$\mathrm{Xu}, \mathrm{H}$. (2006). Modification of normalized difference water index (NDWI) to enhance open water features in remotely sensed imagery. International Journal of Remote Sensing, 27(14), 3025-3033. https://doi.org/10.1080/01431160600589179

Publisher's Note Springer Nature remains neutral with regard to jurisdictional claims in published maps and institutional affiliations. 